\title{
Survey on dairy farm management and infertility problems in small, medium and large scale dairy farms in and around gondar, north west ethiopia
}

\begin{abstract}
Aim: A detailed and organized questionnaire format was designed and an attempt was made to generate base line information with particular emphasis on infertility problems of indigenous and crossbred dairy cows in smallholder, medium and large scale dairy farms in and around Gondar.

Methods: A systematic question was designed and instituted to obtain relevant and reliable information about their animals. The questionnaire were checked for clarity of the questions prior the interview, respondents were briefed to the objective of the study. Following that, the actual questionnaires were presented. Accordingly, a total of $138 \mathrm{SSDF}, 98 \mathrm{MSDF}$ and 7 LSDF dairy owners and attenders were interviewed for the investigation of infertility problems of dairy herds and recorded.

Results: The infertility problems of interviewed dairy owners a total of 384 cross breed and 266 indigenous dairy cows were examined for infertility problems by classifying the method of study as questionnaire survey. In the questionnaire survey $178(50.71 \%)$ and $173(49.29 \%)$ of infertility problems in indigenous \& crossbred cows respectively were recorded.
\end{abstract}

Conclusion: Across all the dairy farm scale there is a problem of infertility, therefore it has a critical influence on dairy cattle production in the area.

Keywords: dairy cows, gondar, infertility, questionnaire survey, scale
Volume 2 Issue 5 - 2015

\author{
Nibret Moges \\ Clinical Medicine Department, University of Gondar, Ethiopia \\ Correspondence: Nibret Moges, Clinical Medicine \\ Department, Faculty of Veterinary Medicine, University of \\ Gondar, P.O.Box 196, Gondar Ethiopia, Tel +25। 091104 3394, \\ Email nibretmoges@yahoo.com
}

Received: March 30, 2015 | Published: October 19, 2015

\section{Introduction}

Ethiopia is one of the sub-Saharan Africa's developing countries with a large potential in livestock population, being 1st among African countries and the 9th in the world. However, meat and milk production are very low, estimated to be 246,000 tones, and 960,000 tones, respectively, with per capital consumption of $17.1 \mathrm{~kg}$ milk and 5.6kg meat per year in 1983-1985. ${ }^{1}$ The cattle population in Ethiopia is estimated to be 41.5 million heads comprising $99.4 \%$ indigenous (Zebu), $0.5 \%$ crossbreeds and $0.1 \%$ exotic breeds which are mainly kept under smallholder subsistence farming. ${ }^{2}$ Livestock production in Ethiopia has been mainly smallholder subsistence farming, with animals having multipurpose use and being managed in a traditional way. In and around Gondar is having total population of 72,979 cattle heads of which 25,935 are accounted for dairy cows. ${ }^{3}$

Agriculture (mainly crop and livestock production) is the mainstay of the Ethiopian economy, employing approximately $85 \%$ of the total population. Livestock production accounts for approximately $30 \%$ of the total agricultural GDP and $16 \%$ of national foreign currency earnings. ${ }^{4}$ Moreover, Ethiopia has diverse animal genetic resources and its relatively large livestock population (approximately 100million) is well adapted to and distributed among diverse ecological conditions and management systems. ${ }^{5}$ In Ethiopia as many developing countries, livestock play multiple roles. Despite the huge number of cattle and their economic importance, the productivity is low due to the constraints of disease, nutrition, poor management and poor performance of indigenous breeds.
The goal of every dairy management team should be to maximize the efficiency of high producing dairy cows so that profitability will increase. Dairying as a component of livestock production is an important economic activity in sub-Saharan Africa. In order to improve the low productivity of local cattle, selection of the most promising breeds and crossbreeding of these indigenous breed with high producing exotic cattle has been considered as a practical solution. The productivity of dairy cattle breeds depends mainly on their reproductive performance and efficiency of service per conception. ${ }^{6}$ The aim of the study was made to generate base line information with particular emphasis on infertility problems of indigenous and crossbred dairy cows in smallholder, medium and large scale dairy farms in and around Gondar, North Western Ethiopia.

\section{Materials and methods}

\section{Study area}

The study was conducted in urban and peri urban areas of Gondar town dairy farms which are located North West part of Ethiopia in Amhara regional state. Gondar town is found about $727 \mathrm{~km}$ from the capital city Addis Ababa. It is located at latitude, longitude, altitude of $12.3-13.8^{\circ} \mathrm{N}, 35.3-35.7^{\circ} \mathrm{E}$ and $2200 \mathrm{~m} . \mathrm{s} .1$, respectively. The annual mean minimum and maximum temperature of the area vary between $12-17^{\circ} \mathrm{C}$ and $22-30^{\circ} \mathrm{C}$, respectively. The area is located under woyna dega, agro-climatic zone and receives a bimodal rainfall the average annual precipitation rate being $1000 \mathrm{~mm}$ that comes from the long and short rainy seasons. The short rainy season occur during the months of 
March, April and May while the long ones extend from June through September. ${ }^{3}$

\section{Sample size}

A sampling frame i.e. the list of the dairy farms was acquired from the urban agricultural development office at the beginning of the study. Dairy farms/cows were selected from this list using a stratified sampling procedure to ensure the selection of proportional and representative sampling of dairy farms and cows. Sampling stratification was done based on number of cows as described by ILRI. 7 Farms owning $(\mathrm{n}=1-2),(\mathrm{n}=3-10)$ and $(\mathrm{n}=11$ and above) cows were taken as to small, medium and large dairy farms, respectively.

\section{Urban and peri-urban dairy farm scale}

The dairy farms considered for this study were categorized into defined strata based on cow herd size; these were small scale dairy farm (SSDF), medium scale dairy farm (MSDF) and large scale dairy farm (LSDF) having 1or 2, 3 to 10 and 11 to above as described by ILRI, respectively.

\section{Questionnaire survey}

A systematic question was designed and instituted to obtain relevant and reliable information about their animals. The questionnaire were checked for clarity of the questions prior the interview, respondents were briefed to the objective of the study. Following that, the actual questionnaires were presented. Accordingly, a total of $138 \mathrm{SSDF}, 98$ MSDF and 7 LSDF dairy owners and attenders were interviewed for the investigation of infertility problems of dairy herds and recorded.

\section{Data collection, management and statistical methods}

The study constituted questionnaire survey on the randomly selected dairy cows. The investigator personally visited all the selected dairy farms, in order to get co-operation of the dairy owners and obtain reliable information about their animals, thorough explanation on the objectives of the study before the start of the interview. The questions were asked about major infertility problems like abortion, dystocia, retained fetal membrane, endometritis, anestrous, repeat breeder, management systems. Data collected from the cross-sectional questionnaire survey was entered in Microsoft excel. Descriptive statistics were used to describe the study dairy farms with respect to farm management and infertility problems. For analysis of the data statistical package for social science (SPSS) (version 18) was used.

\section{Results}

Out of the total interviewed dairy cattle producers $(n=243), 165$ $(67.91 \%)$ were male and the rest $78(32.09 \%)$ were female household members of different age and educational status. Most 165(67.91\%) of the respondents were household heads while the rest were other family members (mainly wives).

The overall proportion of illiterate dairy producers was $39(28.26 \%), 17(17.35 \%)$ from SSDF, MSDF respectively, while $32(23.19 \%)$, 41(41.84 \%) had adult education from SSDF and MSDF, respectively. On the other hand, 38(27.54\%), 17(17.34\%) had religious education from SSDF, MSDF respectively, and 7(100\%) in LSDF dairy farms had above secondary school. With respect to educational status of the household head, the majority of in Gondar dairy producers were literate beyond elementary school. The average family size composition by age group indicated that the majority of household members were within productive age group categories $<18$ years in SSDF 37(26.81\%), MSDF 16(16.33\%) and >18years in SSDF $101(73.19 \%)$, MSDF $82(83.67 \%)$ and in LSDF $7(100 \%)$. The major occupations of various dairy farm systems were presented in Table $1 \&$ Table 2

Inadequate space, reproductive/infertility problem, feed shortage and health problems were stated as the major reasons for culling of cows in SSDF, MSDF and LSDF. In general, in SSDF and MSDF it was common to maintain unproductive animals, especially cows with poor reproductive performance. These probably could be due to lack of external source of replacement animals to maintain or expand herd size (Table 3 \& Table 4).

Table I Proportion of dairy cows in three different dairy farm scales in and around Gondar

\begin{tabular}{lllll}
\hline Category & Total no. of farms & Cross bred cows & Indigenous cows & Total no. of cows \\
\hline SSDF & 138 & 86 & 107 & 193 \\
MSDF & 98 & 196 & 132 & 328 \\
LSDF & 7 & 102 & 27 & 129 \\
Total & 243 & 384 & 266 & 650 \\
\hline
\end{tabular}

SSDF, small scale dairy farm; MSDF, medium scale dairy farm; LSDF, large scale dairy farm

Table 2 Demographic characteristics of sampled households in the study area

\begin{tabular}{lllllll}
\hline Dairy farm scale & & & & & & \\
\hline Variables & SSDF $(\mathbf{n}=\mathbf{1 3 8})$ & $\%$ & MSDF( $\mathbf{n}=\mathbf{9 8})$ & $\%$ & LSDF(n=7) & $\%$ \\
\hline Sex & & & & & & \\
Male & 95 & 68.84 & 63 & 64.29 & 7 & 100 \\
Female & 43 & 31.16 & 35 & 35.71 & --- & ---- \\
Educational status & & & & & & \\
Illiterate & 39 & 28.26 & 17 & 17.35 & \\
\hline
\end{tabular}


Table Continued...

\begin{tabular}{lllllll}
\hline Dairy farm scale & & & & & \\
\hline Variables & SSDF(n=138) & $\%$ & MSDF(n=98) & $\%$ & LSDF(n=7) & $\%$ \\
Educational status & & & & & & \\
Adult Education & 32 & 23.19 & 41 & 41.84 & \\
Primary School & 19 & 13.77 & 13 & 13.27 & \\
Secondary School & 7 & 5.07 & 6 & 6.12 & \\
Above Secondary & 3 & 2.17 & 4 & 4.08 & 7 & \\
Religious Education & 38 & 27.54 & 17 & 17.34 & \\
Family size & & & & & \\
<18 years & 37 & 26.81 & 16 & 16.33 & \\
$>18$ years & 101 & 73.19 & 82 & 83.67 & 7 \\
Major occupation & & & & & \\
Dairy Producer & 24 & 17.39 & 26 & 26.53 & 4 \\
Civil Servant & 10 & 7.25 & 9 & 9.18 & \\
House Wife & 42 & 30.43 & 5 & 5.1 & \\
Pensioner & 12 & 8.7 & 23 & 23.47 & \\
Student & 23 & 16.67 & --- & --- & \\
Merchant & 11 & 7.97 & 12 & 12.24 & 2 \\
Farmer & 12 & 8.7 & 23 & 23.48 & \\
Others & 4 & 2.8 & --- & -- & 1 \\
\hline
\end{tabular}

SSDF, small scale dairy farm; MSDF, medium scale dairy farm; LSDF, large scale dairy farm

Table 3 Purpose and sources of establishment of cows in and around Gondar

\begin{tabular}{|c|c|c|c|c|c|c|}
\hline \multirow{2}{*}{ Variables } & \multicolumn{6}{|c|}{ Dairy farm scale } \\
\hline & $\operatorname{SSDF}(n=138)$ & $\%$ & $\operatorname{MSDF}(n=98)$ & $\%$ & $\operatorname{LSDF}(n=7)$ & $\%$ \\
\hline \multicolumn{7}{|l|}{ Purpose } \\
\hline Milk & 82 & 59.42 & 98 & 100 & 6 & 85.71 \\
\hline Draught & 56 & 40.58 & & & & \\
\hline \multicolumn{7}{|l|}{ Milk/Meat } \\
\hline Milk/Teaching & & & & & 1 & 14.29 \\
\hline \multicolumn{7}{|c|}{ Source of establishment } \\
\hline Purchase & 34 & 24.63 & 31 & 31.63 & & \\
\hline Gift From Family & 47 & 34.06 & 18 & 18.37 & & \\
\hline Farm Bred & 36 & 26.09 & 39 & 39.8 & 7 & 100 \\
\hline Farm bred \& Purchase & 21 & 15.22 & 10 & 10.2 & & \\
\hline
\end{tabular}

Table 4 Culling reasons of cows in different dairy farm scales

\begin{tabular}{lllllll}
\hline \multirow{2}{*}{ Culling reasons } & \multicolumn{7}{l}{ Dairy farm scale } & & & \\
\cline { 2 - 7 } & SSDF(n=138) & $\%$ & MSDF(n=98) & $\%$ & LSDF(n=7) & $\%$ \\
\hline Inadequate Space & 39 & 28.26 & 16 & 16.33 & 4 & 57.13 \\
Feed Shortage & 32 & 23.19 & 25 & 25.51 & I & 14.29 \\
Reprod./Infertility Problems & 36 & 26.09 & 22 & 22.45 & I & 14.29 \\
Old Age & 4 & 2.9 & 2 & 2.04 & & \\
\hline
\end{tabular}


Table Continued.

\begin{tabular}{lllllll}
\hline \multirow{2}{*}{ Culling reasons } & \multicolumn{3}{c}{ Dairy farm scale } & & & \\
\cline { 2 - 6 } & SSDF(n=138) & $\%$ & MSDF(n=98) & $\%$ & LSDF(n=7) & \% \\
\hline Health Problems & II & 7.97 & 18 & 18.37 & 1 & 11.22 \\
Poor Production & 8 & 5.8 & 11 & 4.08 \\
Financial Requirement & 6 & 4.35 & 4 & & \\
Others & 2 & 1.44 & &
\end{tabular}

SSDF, small scale dairy farm; MSDF, medium scale dairy farm; LSDF, large scale dairy farm

The feeds were of natural pasture, purchased concentrates, beer brewery and roughages conventional and non conventional feeds. The majority $64(46.38 \%)$ of the households in SSDF used grazing on communal grazing and stall feeding, 52(37.68\%) used only grazing and about 22(15.94\%) other sources. In MSDF 71(72.45\%) dairy farms were used grazing and stall feeding and 19(19.39\%) used only grazing. In LSDF 1(14.29\%) were used stall feeding and 6(85.71\%) dairy farms were used grazing and stall feeding. In contrary to this, $18(13.04 \%), 68(69.39 \%)$ and $2(28.57 \%)$ of dairy producers in SSDF, MSDF and LSDF used hay respectively. In addition, 30(30.61\%), $5(71.43 \%)$ MSDF and LSDF respectively purchased feeds from different sources. The rest use road side grazing and own feed resources (Table $5 \&$ Table 6 ).

The infertility problems of interviewed dairy owners a total of 384 cross breed and 266 indigenous dairy cows were examined for infertility problems by classifying the method of study as questionnaire survey. In the questionnaire survey $178(50.71 \%)$ and $173(49.29 \%)$ of infertility problems in indigenous \& crossbred cows respectively were recorded.

Owner of 384 cross breed cows were questioned for major infertility problems and found 29(8.73\%) post partum anoestrus, $46(13.85 \%)$ retained fetal membrane, $16(4.82 \%)$ abortion, 32(9.63\%) dystocia, $13(3.91 \%)$ clinical endometritis and 26(7.83\%) repeat breeder. In addition 266 indigenous dairy cows owners were questioned for infertility problems by classifying the method of study as questionnaire survey and found $54(16.27 \%)$ post partum anoestrus, $15(4.51 \%)$ retained fetal membrane, $27(8.13 \%)$ abortion, $20(6.02 \%)$ dystocia, $7(2.10 \%)$ clinical endometritis and $47(14.15 \%)$ repeat breeder (Table 6).

Table 5 Feeding systems practiced and proportional utilization of feed resources

\begin{tabular}{|c|c|c|c|c|c|c|}
\hline \multirow{2}{*}{ Variables } & \multicolumn{6}{|c|}{ Dairy farm scale } \\
\hline & $\operatorname{SSDF}(n=138)$ & $\%$ & $\operatorname{MSDF}(n=98)$ & $\%$ & $\operatorname{LSDF}(n=7)$ & $\%$ \\
\hline \multicolumn{7}{|l|}{ Feeding practice } \\
\hline Only Grazing & 52 & 37.68 & 19 & 19.39 & & \\
\hline Stall Feeding & 22 & 15.94 & 8 & 8.16 & 1 & 14.29 \\
\hline Grazing and Stall Feeding & 64 & 46.38 & 71 & 72.45 & 6 & 85.71 \\
\hline \multicolumn{7}{|l|}{ Main feed types } \\
\hline Natural Pasture & 80 & 57.97 & & & & \\
\hline Hay & 18 & 13.04 & 68 & 69.39 & 2 & 28.57 \\
\hline Crop Residue & 15 & 10.87 & & & & \\
\hline Oilseed Cakes & 17 & 12.32 & 13 & 13.27 & 2 & 28.57 \\
\hline Beer Brewery & 8 & 5.8 & 8 & 8.16 & 1 & 14.29 \\
\hline Concentrates & & & 9 & 9.18 & 2 & 28.57 \\
\hline
\end{tabular}


Table 6 Interviewed dairy owners the relative occurrence of major infertility problems

\begin{tabular}{|c|c|c|}
\hline Type of infertility & $\begin{array}{l}\text { Questionnaire survey } \\
\text { result }\end{array}$ & Percent \\
\hline \multicolumn{3}{|c|}{ Post partum anoestrus } \\
\hline cross & 29 & 8.73 \\
\hline local & 54 & 16.27 \\
\hline \multicolumn{3}{|l|}{ Abortion } \\
\hline cross & 16 & 4.82 \\
\hline local & 27 & 8.13 \\
\hline \multicolumn{3}{|l|}{ Dystocia } \\
\hline cross & 32 & 9.63 \\
\hline local & 20 & 6.02 \\
\hline \multicolumn{3}{|c|}{ Clinical endometritis } \\
\hline cross & 13 & 3.91 \\
\hline local & 7 & 2.1 \\
\hline \multicolumn{3}{|l|}{ Repeat breeder } \\
\hline cross & 26 & 7.83 \\
\hline local & 47 & 14.15 \\
\hline \multicolumn{3}{|c|}{ Retained fetal membrane } \\
\hline cross & 46 & 13.85 \\
\hline local & 15 & 4.51 \\
\hline \multicolumn{3}{|l|}{ Still birth } \\
\hline cross & 11 & 3.13 \\
\hline local & 8 & 2.28 \\
\hline Total & 351 & 100 \\
\hline
\end{tabular}

\section{Discussion}

Infertility in indigenous and crossbred cows was the major cause of economic loss for dairy farming. Out of 650 cows during this study $351(54 \%)$ cows were found with one of the infertility problems. The result agrees with Desalegn ${ }^{8}$ reported in Ada district zone 56.5\%, 62\% Ebrahim $^{9}$ and Molalegne $43.7 \%,{ }^{10}$ around in district Bedelle, similar incidence were reported Shiferaw et al. ${ }^{11} 39 \%$ in central highlands of Ethiopia which have the same environmental condition with that of Gondar. On the contrary Gebremariam ${ }^{12}$ in Mekelle reported 29.1\%. Emebet and Zeleke ${ }^{13}$ in Dire Dawa 30.8\%, 26.7\% in Kombolcha, Haftu and Gashaw ${ }^{14} 21.6 \%$ in Bako and Yimer ${ }^{15}$ which is $39.9 \%$ in Woliso which were lower than in the present study this could be probably due to environmental conditions which was different from that of Gondar.

The incidence of dystocia recorded in the present study was $5.15 \%$ which is in line with the previously documented dystocia incidence in Ireland. ${ }^{16}$ Cows that experienced dystocia had a longer interval to first service which is likely due to a delayed resumption of cyclicity post-calving. Cows that experienced dystocia also required more inseminations and therefore also had longer calving intervals. The probability of the cow surviving to subsequent lactation was also reduced for cows that experienced dystocia $(-0.08)$ compared to cows with no dystocia. The average reduction in milk yield across the first 60days in milk $(-36.13 \mathrm{~kg})$ for cows that experienced dystocia at calving was consistent with a previous study in New Zealand $(-42.0 \mathrm{~kg})$. Similarly fat $(-1.58 \mathrm{~kg})$ and protein $(-1.18 \mathrm{~kg})$ yield were also reduced in cows that experienced dystocia at calving. ${ }^{14}$

The significantly higher incidence of infertility problems encountered in crossbred cows $59.6 \%$ than in indigenous zebu $52.6 \%$ which may be due to the fact that European cross breeds are less adapted to tropical conditions, diseases and low feed quality than zebu cattle Mugerwa ${ }^{17}$ making them more susceptible than indigenous zebu. Another reason may also be due to the fact that, cross breeds require more elaborated management, feeding and better health care than the indigenous zebu to get better fertility and productivity in the tropics. $^{16}$

Detailed research has illustrated that some of the pathophysiological pathways explaining the association between the increase in milk production and the decrease infertility. It has been reported that production levels go along with a deeper and more prolonged negative energy balance as can be measured by lowered levels of glucose, insulin growth factor 1 and insulin, and elevated levels of metabolites like ketone bodies and urea. As most of these metabolites are able to reach the ovaries and affect several cell types and hence negatively influence fertility. ${ }^{18}$

Contrary to the widely accepted profile of declining fertility, Wischral et al., ${ }^{19}$ suggested that declining herd fertility has been happening only in some farms but not in all. The latter reflects a significant herd variation in the occurrence of risk factors for reduced fertility, and proves that acceptable fertility performances are still feasible even in herds with very high productions.

In the present study, multiparous cows $60.15 \%$ emaciated cows $60.00 \%$ and cows above 6 years of age $62.73 \%$ were the most affected by infertility problems which is higher than the previous finding by Takele et al., ${ }^{16}$ that were recorded $19.23 \%$ in and around Nazareth town. This could be due to the repeated exposure of the genital tract of multiparous cows to environmental pathogenic microorganisms then causing gradual decrease in the efficiency of immune mechanism due to ageing.

Infertility in indigenous and crossbred cows was the major cause of economic loss for dairy farming. Out of 650 cows during this study $351(54 \%)$ cow s were found with one of the infertility problems. The incidence of dystocia recorded in the present study was $5.15 \%$ which is in line with the previously documented dystocia incidence in Ireland. ${ }^{16}$ Cows that experienced dystocia had a longer interval to first service which is likely due to a delayed resumption of cyclicity post-calving. Cows that experienced dystocia also required more inseminations and therefore also had longer calving intervals. The probability of the cow surviving to subsequent lactation was also reduced for cows that experienced dystocia (-0.08) compared to cows with no dystocia. The average reduction in milk yield across the first 60days in milk $(-36.13 \mathrm{~kg})$ for cows that experienced dystocia at calving was consistent with a previous study in New Zealand $(-42.0 \mathrm{~kg})$. Similarly fat $(-1.58 \mathrm{~kg})$ and protein $(-1.18 \mathrm{~kg})$ yield were also reduced in cows that experienced dystocia at calving. ${ }^{14}$

\section{Conclusion}

Most of the dairy farms from in SSDF, MSDF and LSDF, had fallen below satisfactory or poor farm hygiene. This was due to lack of sufficient space in the compound and inadequate knowledge 
about hygienic management. Across all the dairy farm scale there is a problem of infertility, therefore it has a critical influence on dairy cattle production in the area.

\section{Acknowledgements}

None.

\section{Conflict of interest}

Author declares that there is no conflict of interest.

\section{References}

1. ESAP (Ethiopian Society of Animal production). Ruminant livestock development strategy. Newsletter of the Ethiopian Society of Animal production (ESAP), Addis Ababa, Ethiopia; 1995;3(1-2).

2. MOA budgeting and planning reports, summary of MOA. North Gondar zone; 2004;1:14-20.

3. Central Statistical Authority (CSA). Report on livestock and livestock characteristics. Addis Ababa, Ethiopia: Agriculture Sample Survey, 2008 .

4. IBC (Institute of biodiversity conservation). The state of Ethiopia's farm animal genetic resources country report. A contribution to the first Report on the state of the worlds Animal Genetic Resources. 2004.

5. Lobago FM, Bekana H Gustafsso, Kindahl H. Reproductive performances of dairy cows in smallholder production system in Selalle, Central Ethiopia. Trop Anim Health prod. 2006;38(4):333-342.

6. Tadesse B. Reproductive performances of zebu (fogera) breed in the central highlands of Ethiopia. Debre Zeit, Ethiopia: DVM thesis, Addis Ababa University, Faculty of Veterinary Medicine. 2002

7. ILRI. Annual project report. Addis Ababa, Ethiopia; 1996. 2-4p.

8. Desalegn M. Study on major Infertility problems of cross breed dairy herds in Ada'a district of central Ethiopia. Debrezeit, Ethiopia: DVM thesis, Addis Ababa University. Faculty of veterinary medicine. 2000.
9. Ebrahim OM. Study on major Reproductive Health problems of small holder dairy farms in and around Kombolcha. DVM thesis, Addis Ababa University. Debrezeit, Ethiopia: Faculty of veterinary medicine, 2003.

10. Molalegene B, Shiv P. Study on Major Reproductive Health Problems in Indigenous and Cross Breed Cows in and Around Bedelle, South West Ethiopia. Journal of Animal and Veterinary Advances 2011;10(6):723-727.

11. Shiferaw. Reproductive disorders of crossbred dairy cattle in the Central Highlands of Ethiopia and their effect on reproductive performance. Tropical Animal Health and Production. 2005;37(5):427-441.

12. Gebremariam T. Survey on major prepartum and post partum reproductive problems of dairy cattle in Mekelle and around Nazareth town, central Ethiopian. Int J vet Med. 1996;16:3-7.

13. Emebet M, Zeleke M. Reproductive performance of crossbred dairy cows in eastern lowlands of Ethiopia. Livestock Research for Rural Development. 2007;19(11).

14. Haftu B, Gashaw A. The prevalence of reproductive problems in cross bred dairy cows in and around Bako. West Ethiopia, Jimma University, College of agriculture and veterinary Medicine. 2009.

15. Yimer E. Major reproductive health problems in small holder dairy farms in and around Woliso. Debrezeit, Ethiopia: DVM thesis, Addis Ababa University. Faculty of veterinary medicine, 2005.

16. Takele AY Gizaw, Bekan M. Major Reproductive health problems in Smallholder dairy production in and around Nazareth town, Central Ethiopia. Debrezeit, Ethiopia: Faculty of Veterinary Medicine, Addis Ababa University. 2005:6-17.

17. Mugerwa EM. A review of a productive performance of female Bosindicus (zebu) cattle. Addis Ababa, Ethiopia: ILCA Monograph 6. ILCA, 1989.

18. Sheldon IM. The postpartum uterus. Vet Clin North Am Food Anim Pract 2004;20(3):569-591.

19. Wischral A, Verreschi IT, Lima SB, et al. Pre-parturition profile of steroids and prostaglandin in cows with or without foetal membrane retention. 2001;67(3-4):181-188. 